\title{
Cytokeratins 18 and 8 are poor prognostic markers in patients with squamous cell carcinoma of the oesophagus
}

\author{
T Makino', M Yamasaki",', A Takeno', M Shirakawa', H Miyata', S Takiguchi', K Nakajima', Y Fujiwara', \\ T Nishida', N Matsuura', $M$ Mori' and Y Doki' \\ 'Department of Gastroenterological Surgery, Graduate School of Medicine, Osaka University, 2-2-E2, Yamada-oka, Suita, Osaka 565-087I, Japan; \\ ${ }^{2}$ Department of Molecular Pathology, School of Allied Health Science, Faculty of Medicine, Osaka University, 2-2-E2, Yamada-oka, Suita, Osaka \\ 565-087I, Japan
}

\begin{abstract}
BACKGROUND: Cytokeratins (CKs) are structural marker proteins specific for epithelial cells. However, recent studies indicate their involvement in cancer progression.

METHODS: We evaluated CKI 8 and its filament partner, CK8 expression, by immunohistochemistry in 210 resected specimens from patients with oesophageal squamous cell carcinoma (OSCC). We also analysed the relationship between their expression and various clinicopathological parameters including prognosis.

RESULTS: Neither CKI8 nor CK8 was expressed in non-cancerous squamous epithelium whereas proper oesophageal glands expressed both CKs. Ninety (42.9\%) tumours were CKI 8 positive and 85 (40.5\%) CK8 positive, and the concordance rate for immunohistochemical classification for CKI 8 and CK8 was $82.4 \%$. CKI 8 expression correlated with poorly differentiated tumours, use of neo-adjuvant chemotherapy, and advanced stage. Prognosis of patients with CKI8-positive tumours was poorer than that of patients with negative OSCC $(P<0.00 \mathrm{I})$. A similar trend was noted for CK8 expression. Multivariate analysis identified $\mathrm{PT}$ $(P=0.020)$, $p N$ number $(P=0.001)$, and $C K I 8$ expression $(P=0.004)$ as independent prognostic factors. CKI 8 expression in 83 pretreatment biopsy specimens was detected in 47 cases $(56.6 \%)$ and also correlated with prognosis $(P=0.045)$.

CONCLUSION: CKI8/CK8 expression correlated with progression of OSCC. The significant correlation with prognosis and stable expression in biopsy specimen suggest usefulness of CKI 8 in selection of treatment strategies for OSCC.

British Journal of Cancer (2009) I I , 1298-1306. doi:I0.1038/sj.bjc.66053I3 www.bjcancer.com

Published online 15 September 2009

(C) 2009 Cancer Research UK
\end{abstract}

Keywords: cytokeratin 8 (CKI8); cytokeratin8 (CK8); oesophageal squamous cell carcinoma (OSCC); immunohistochemistry (IHC); quantitative reverse transcription polymerase chain reaction (RT-PCR)

Oesophageal squamous cell carcinoma (OSCC), the major histopathological form in East Asian countries, is one of the most lethal malignancies of the digestive tract and frequently diagnosed at advanced stage (Shimada et al, 2003). Although surgical resection is one of the most reliable treatments in OSCC, disease recurrence often occurs even after curative resection. Earlier reports suggested the usefulness of preoperative chemotherapy/ chemoradiotherapy and postoperative chemotherapy in OSCC (Fiorica et al, 2004; Ando et al, 2003; Kaklamanos et al, 2003; Tepper et al, 2008). For effective indication of these therapeutic modalities, it is necessary to identify those patients with poor prognosis who are best candidates for these therapies. So far, pathological findings based on examination of resected specimen are the most reliable information for prediction of clinical outcome, however, the predictive values of these variables remain unsatisfactory and not available for preoperative setting. There-

*Correspondence: Dr M Yamasaki; Department of Gastroenterological Surgery, Graduate School of Medicine, Osaka University, 2-2-E2, Yamada-oka, Suita, Osaka, 565-087I Japan;

E-mail: myamasaki@gesurg.med.osaka-u.ac.jp

Received 18 May 2009; revised 12 August 2009; accepted 17 August 2009; published online 15 September 2009 fore, there is a need for the development of novel biological markers that can accurately distinguish high-risk population of recurrent disease by combining conventional TNM classification (Sobin, 2002), for more appropriate treatment strategy.

Cytokeratin (CK), an intermediate filament observed mainly in epithelial cells, is an essential cytoskeletal component involved in fixation of the nucleus and maintenance of cell morphology. The cytoskeleton of epithelia is formed by 20 subtypes of CKs whose expression depends primarily on epithelial cell type and degree of differentiation (Chu and Weiss, 2002a). These CKs are divided into two groups; type I (acidic, CK9-20) and type II (neutral-basic, CK1-8) gene families (Moll et al, 1982; Hesse et al, 2001). In non-cancerous tissue, CK18 and its co-expressed complementary subunit, CK8, are commonly expressed in normal glandular epithelia, transitional cell epithelium, and hepatocyte, but not in squamous stratified epithelium (Debus et al, 1984; Schaafsma et al, 1990; Trask et al, 1990; Schussler et al, 1992). Interestingly, in cancerous tissue, adenocarcinomas, such as human breast or colorectal carcinoma frequently show reduced CK8/18 expression, which correlates with tumour progression and poor outcome (Woelfle et al, 2004; Knosel et al, 2006). On the other hand, CK8/18 expression is upregulated in head and neck carcinoma (Xu et al, 1995; Gires et al, 2006), oral cavity carcinoma (Fillies et al, 2006), and transitional cell carcinoma of the urinary 
tract (Schaafsma et al, 1990; Southgate et al, 1999), and is associated with unfavourable prognosis (Fillies et al, 2006). In vitro analysis demonstrated the malignant role of CK8/18 expression, indicating that various CK8/18-overexpressing cell lines, such as human lung adenocarcinoma (Chu et al, 1997), human melanoma cells (Chu et al, 1996), and mouse L cells (Chu et al, 1993), have higher migratory/invasive abilities compared with the control.

Apart from CK8/18, earlier reports described loss of CK7 and acquisition of CK20 in colorectal carcinoma (Park et al, 2002), acquisition of CK7, and loss of CK20 in gastric carcinoma (Park et al, 2002; Kim et al, 2004), and acquisition of CK1, 5, 6, 8, 19 in squamous cell carcinoma (Xu et al, 1995; Chu and Weiss, 2002a, b; Ikeda et al, 2008). Thus, it seems that CK expression in epithelial tissues can change with differentiation or malignant transformation (Hendrix et al, 1996) in an organ-specific manner (Kurokawa et al, 2006). Although earlier reports indicated upregulation of $\mathrm{CK} 8 / 18$ in OSCC during the pre-cancerous and cancerous stages (Grace et al, 1985; Lam et al, 1995; Takahashi et al, 1995; Viaene and Baert, 1995; Cintorino et al, 2001), to our knowledge, their role in prognosis has not been evaluated. Here, we assessed CK18 and CK8 expression levels in OSCC by using a series of 210 resected specimens. Furthermore, considering the clinical application of these CKs in the future, we also examined the expression levels of CK18 in biopsy specimens obtained by endoscopy.

\section{PATIENTS AND METHODS}

\section{Patients and treatments}

This retrospective study involved 210 patients with thoracic oesophageal cancer who underwent surgical resection in our hospital from 1998 to 2007. All 210 patients were confirmed to have OSCC by histopathological examination of endoscopic biopsy and considered suitable for surgery based on preoperative assessment. They included 23 females and 187 males, aged between 38 and 82 (median, 63.1 years). Table 1 lists patient characteristics. Of the total, 110 patients with $\mathrm{cN} 1$ received neo-adjuvant chemotherapy (NACT), which consisted of two courses of 5-fluorouracil (5-FU), cisplatin (CDDP), and adriamycin (ADM) (Akita et al, 2006; Yano et al, 2006; Matsuyama et al, 2007; Makino et al, 2008). Curative resection (R0), that is, oesophagectomy with two- or three-field lymphadenectomy, was performed in 199 patients $(94.8 \%)$, whereas non-curative resection (R2) was carried out in the remaining 11 patients $(5.2 \%)$; these patients were excluded from the survival analysis. None of the patients died of

Table I Patients characteristics $(n=210)$

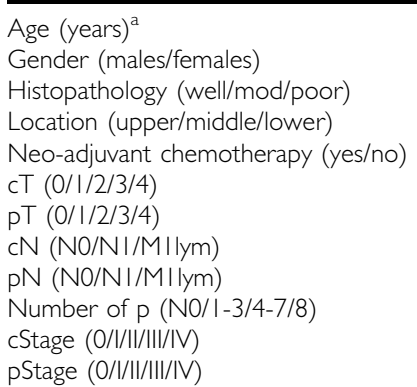

$63.1(38-82)$

$187 / 23$

$48 / 107 / 55$

$27 / 101 / 82$

$110 / 100$

$0 / 28 / 63 / 94 / 25$

$0 / 39 / 35 / 120 / 16$ $67 / 143 / 46$

$61 / 149 / 51$

$59 / 85 / 26 / 40$

$0 / 20 / 72 / 72 / 46$

$0 / 18 / 75 / 66 / 51$

${ }^{a}$ Data are average and (range). Well/mod/poor=well, moderately, and poorly differentiated squamous cell carcinoma; upper/middle/lower=middle, lower, and upper thoracic oesophagus. cT, cN, cStage (clinical classification); pN, pT, pStage (pathological classification); and MIlym (distant lymph node metastasis) are based on TNM classification. postoperative complications. Sixty-five patients with multiple metastatic lymph nodes in the surgical specimen received docetaxel or CDDP plus 5-FU postoperatively (Ando et al, 2003). In our hospital, patients with OSCCs that invade the airway or major blood vessels or accompanied by visceral metastasis are not indicated for surgery and therefore receive chemoradiotherapy or chemotherapy alone.

After surgery, the patients were surveyed every 3 months by physical examination and serum tumour markers, every 6 months by CT scan and abdominal ultrasonography, and every year by endoscopy until tumour recurrence was evident. Patients with tumour recurrence received chemotherapy or chemoradiotherapy, as long as their systemic condition permitted. The mean overall survival (OS) was 34.9 months and mean disease-free survival (DFS) was 22.2 months. The mean follow-up period after surgery was 38.8 months. This study was approved by the Human Ethics Review Committee of Osaka University School of Medicine and a signed consent form was obtained from each subject.

\section{Quantitative reverse transcription polymerase chain reaction analysis}

Total RNA was extracted from fresh frozen tissue of resected tumours in 21 out of total 210 OSCCs using TRIzol Reagent (Invitrogen, Carlsbad, CA, USA). Complementary DNA (cDNA) was generated from $1 \mu \mathrm{g}$ RNA in a final volume of $20 \mu \mathrm{l}$, containing oligo- $(\mathrm{dT})_{15}$ primer, avian myeloblastosis virus transcriptase, with reverse transcription (RT) system (Promega, Madison, WI, USA). Polymerase chain reaction (PCR) analysis was performed by using LightCycler, a real-time monitoring thermal cycler. Polymerase chain reaction reaction mixture was prepared containing $2 \mu \mathrm{l}$ of cDNA template, $3 \mathrm{mmoll}^{-1} \mathrm{MgCl}_{2}, 250 \mathrm{nmoll}^{-1}$ of primer pairs, using LightCycler FastStart DNA Master SYBR Green I (Roche Diagnostics, Mannheim, Germany). The amount of each transcript was normalised against the expression of the housekeeping gene, glydecaldehyde-3-phosphate-dehydrogenase (GAPDH). Standard curve was constructed with 10 -fold serial dilutions of cDNA obtained from non-cancerous oesophageal mucosal cell layers of tissue samples from 10 cases as a standard mixture. The sequences of PCR primers for GAPDH, CK18, and CK8 were as follows: forward primer 5'-CAACTACATGGTTTACATGTTC-3', reverse primer $5^{\prime}$-GCCAGTGGACTCCACGAC-3' used for amplification of GAPDH, forward primer $5^{\prime}$-ATCTTGGTGATGCCTTGGAC-3', reverse primer $5^{\prime}$-CCTGCTTCTGCTGGCTTAAT- $3^{\prime}$ for CK18, and forward primer $5^{\prime}$-TAGCACTGGGAACAGGAGA-3', reverse primer 5'-TTTGACATTGGCAGAGCTA-3' for CK8. The PCR cycling condition was set as follows: an initial denaturing step at $95^{\circ} \mathrm{C}$ for $10 \mathrm{~min}$ and $40 \mathrm{cycles}$ at $95^{\circ} \mathrm{C}$ for $15 \mathrm{~s}, 58^{\circ} \mathrm{C}$ for $10 \mathrm{~s}$, and $72^{\circ} \mathrm{C}$ for $25 \mathrm{~s}$. The relative amount of cDNA in each sample was measured by interpolation on the standard curve, and then the relative ratio of CK18/GAPDH mRNA or CK8/GAPDH mRNA expression in log2 scale was calculated for each OSCC sample.

\section{Immunohistochemical analysis}

The amounts of CK18 and CK8 proteins in the tissues were examined by immunohistochemical staining of formalin-fixed and paraffin-embedded serial sections. One representative slide with the deepest tumour invasion was selected from each patient and subjected to immunohistochemistry using the streptavidinperoxidase method. Briefly, after deparaffinisation in xylene and dehydration in graded ethanol, endogenous peroxidase activity was blocked by incubation with $30 \mathrm{mll}^{-1}$ hydrogen peroxide for $20 \mathrm{~min}$. Then tissue sections were heated for $40 \mathrm{~min}$ at $95^{\circ} \mathrm{C}$ in citrate buffer $\left(0.05 \mathrm{moll}^{-1}, \mathrm{pH}\right.$ 6.0) for antigen retrieval. After incubation with mouse monoclonal primary antibody DO10 (Bartek et al, 1991) (Novocastra, Newcastle, UK, dilution 1:40) 
for CK18 and TS1 (Johansson et al, 1999) (Novocastra, dilution $1: 200$ ) for CK8 for $14 \mathrm{~h}$, the sections were stained by the labelled streptavidin biotin method. Negative controls of immunohistochemical reactions were performed by omitting the primary antibody. Positive staining of normal oesophageal gland at the non-cancerous area in the same section was used as an internal positive control. Furthermore, CK18 immunoreactivity was examined using the same antibody and methods in pretreated fiberscopic biopsy samples obtained from 83 of the 210 patients. The presence of CK18 or CK8 protein was judged 'positive' when the proportion of immunohistochemically stained cells was more than $50 \%$ of all observed cancer cells (Lam et al, 1995), or otherwise 'negative'. All slides were assessed by two observers independently and then in conference in a blinded manner without any prior knowledge of the clinicopathological parameters. Characteristically, immunostaining of CK family of proteins yields clearly recognised tumour cells with sufficient intensity and frequency, with little or no background or non-specific staining. Therefore, the judgment of immunostaining was always consistent between the two observers and the results were the same on different cut-off lines around $10-50 \%$ of the proportion of immunohistochemically stained cells.

\section{Western blot analysis}

Western blot analysis was performed to confirm the specificity of CK18 and CK8 antibodies (Miyata et al, 2001). Briefly, the protein extracted from tissue samples $(20 \mu \mathrm{g})$, MCF7 whole cell lysates $(0.5 \mu \mathrm{g})$ and recombinant protein of each CK18 and CK8 (ProSpecTany Technogene, Rehovot, Israel) $(0.1 \mu \mathrm{g})$ were separated using 7.5\% polyacrylamide gel electrophoresis, followed by electroblotting onto a polyvinylidene difluoride membrane. The membrane was incubated with the primary antibodies at appropriate concentrations (anti-CK18 1:200 dilution, anti-CK8 1:500 for $12 \mathrm{~h}$ at $4{ }^{\circ} \mathrm{C}$, and anti-actin $1: 2000$ for $1 \mathrm{~h}$ at room temperature). Protein bands were detected using the Amersham-enhanced chemiluminescence detection system (Amersham Biosciences Corp., Piscataway, NJ, USA).

\section{Statistical analysis}

Data are expressed as mean \pm s.d. Differences in continuous parameters between two groups classified by CK18 or CK8 protein expression were evaluated by the Mann-Whitney's $U$ test. Correlations between CK18 expression on immunohistochemistry and various clinicopathological parameters were evaluated by the $\chi^{2}$ test and Fisher's exact probability test. Regression analysis was used to determine the correlation between CK18 and CK8 gene expressions using Pearson's correlation coefficient ( $R$ value). Prognostic variables were assessed by the log-lank test, and DFS and OS were analysed by the Kaplan-Meier test. Cox's proportional hazard regression model with stepwise comparison was used to analyse the independent prognostic factor(s). All statistical analyses were carried out using SPSS for Windows release 10 (SPSS, Inc, Chicago, IL, USA). A $P$-value of $<0.05$ was accepted as statistically significant.

\section{RESULTS}

Cytokeratins 18 and 8 expression in oesophageal squamous cell carcinoma

Non-cancerous squamous epithelium showed no immunohistochemical staining for both $\mathrm{CK} 18$ and $\mathrm{CK} 8$, but adjacent proper oesophageal glands always showed strong immunostaining for both, which served as an internal positive control (Figure 1A and B). All 210 samples, including cancer and non-cancerous lesions in the same section, were evaluated for CK18 and CK8
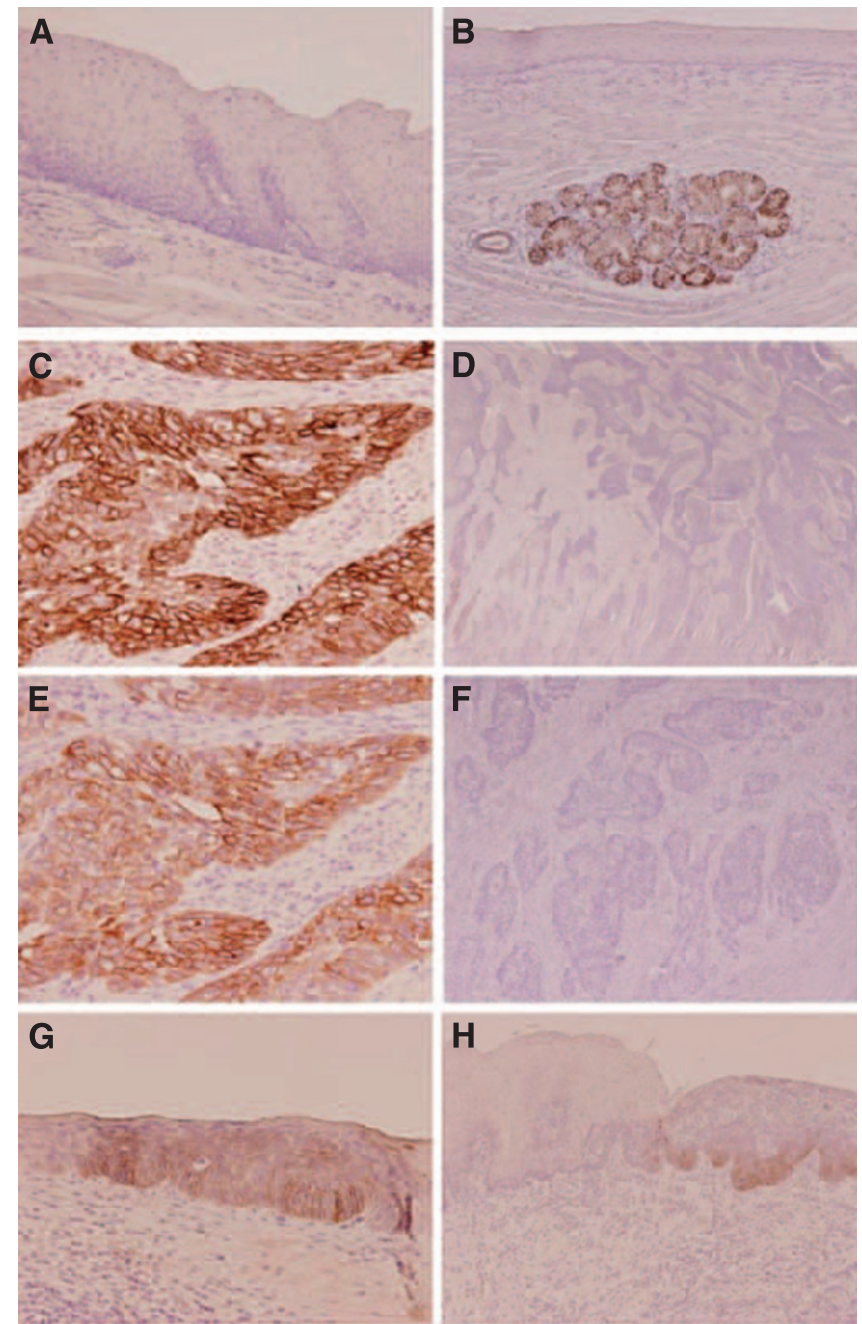

H

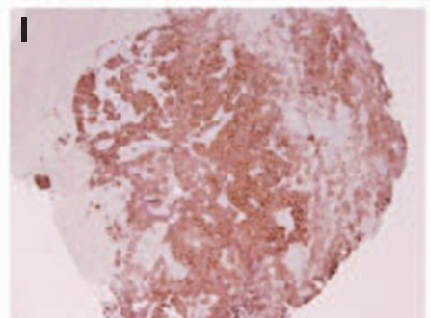

Figure I CKI8/CK8 expression by immunohistochemical staining. (A) Normal squamous epithelium was negative for CKI8 (magnification $\times$ 100). (B) Normal oesophageal glands showed positive staining for CKI8, which was used as an internal control (magnification $\times 200$ ). $(\mathbf{C}, \mathbf{E})$ Representative examples of CKI8-positive (C) and CK8-positive (E) oesophageal squamous cell carcinomas, which showed staining in more than 10\% of all tumour cells (magnification C, E $\times 200$ ). (D, F) CKI8negative (D) and CK8-negative (F)- oesophageal squamous cell carcinomas showed almost no appreciable staining of tumour cells (magnification D $\times 20, \mathbf{F} \times 40) .(\mathbf{G}, \mathbf{H}) \mathrm{CKI} 8(\mathbf{G})$ and $\mathrm{CK} 8(\mathbf{H})$ immunostaining in intraepithelial neoplasia (magnification $\mathbf{G} \times 200, \mathbf{H} \times 100$ ). (I) CKI 8-positive oesophageal squamous cell carcinoma in a pretreatment biopsy specimen (magnification $\times 40$ ).

protein expression by immunohistochemical analysis (IHC) respectively. Positive CK18 expression was identified in 90 $(42.9 \%)$ cases, and the staining was mainly observed in the cytoplasm of tumour cells. The remaining $120(57.1 \%)$ cases were negative (Figure 1C and D). Furthermore, 85 (40.5\%) cases showed positive immunostaining for CK8 in the cytoplasm of tumour cells, whereas 125 (59.5\%) were negative (Figure 1E and F). The positive 
staining for CK18/8 was almost homogeneous at single cancer nest and among different areas (surface, central, and deepest areas) of the cancer lesion. There was a significant correlation between CK18 and CK8 immunostaining $(P<0.001) ; 69$ (32.9\%) patients showed positive immunostaining for both CK18 and CK8, with largely matching distribution, whereas $104(49.5 \%)$ were negative for both. On the other hand, 37 (17.6\%) patients showed discordant immunostaining, including CK18 positive and CK8 negative in 21 cases, and CK18 negative and CK8 positive in 16 (Table 2). Intra-epithelial neoplasia (dysplasia) was observed in 55 cases. Among them, CK18 and CK8 expressions were detected in $13(23.6 \%)$ and $14(25.5 \%)$ cases, respectively (Figure $1 \mathrm{G}$ and $\mathrm{H}$ ).

Western blot analysis demonstrated strong expression of CK18 and CK8, with molecular weights of 45 and $52.5 \mathrm{kDa}$, respectively, in whole cell lysates of MCF7 and recombinant proteins of CK18 and CK8. In cancer tissue obtained from one representative patient positive for both CK18 and CK8 expression by immunohistochemistry, CK18 and CK8 were strongly expressed, but not in normal squamous epithelial cells (Figure 2).

Quantitative RT - PCR analysis was performed in 21 representative cases to elucidate the mechanisms of gene transcription and the relationship between protein and mRNA expression levels of these molecules. It showed the expression level of CK18 mRNA in CK18-positive tumours $(n=5)$ was significantly higher than that in CK18-negative cases $(n=16) \quad(1.78 \pm 0.92$ vs $-0.001 \pm 0.87$, $P=0.005)$. Similarly, the expression level of CK8 mRNA in CK8positive tumours $(n=6)$ was significantly higher than that in CK8negative cases $(n=15) \quad(3.08 \pm 1.46$ vs $0.84 \pm 1.75, \quad P=0.016)$ (Figure 3). Regression analysis showed a significant correlation between CK18 and CK8 mRNA expression $(R=0.822, R 2=0.675$, $P<0.001)$.

Table 2 Correlation between CKI8 and CK8 protein accumulation examined by immunohistochemical staining

\begin{tabular}{lccc}
\hline & \multicolumn{3}{c}{ CK8 } \\
\cline { 2 - 4 } & Positive & Negative & Total \\
\hline CKI8 & 69 & 21 & $90(42.9 \%)$ \\
Positive & 16 & 104 & $120(57.1 \%)$ \\
Negative & $85(40.5 \%)$ & $125(59.5 \%)$ & $210(100 \%)$ \\
Total & & &
\end{tabular}

$P<0.000$ I by Fisher's exact test.

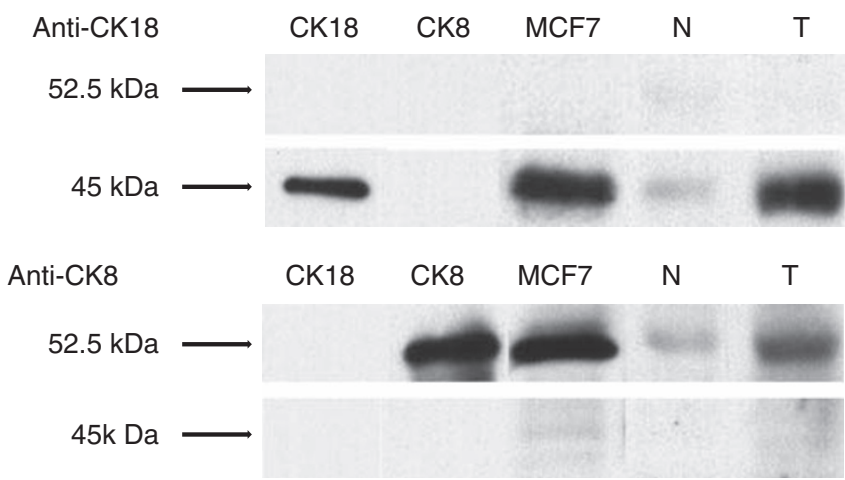

Figure 2 CKI8/CK8 expression by western blot analysis. Each CKI 8 and CK8 expression was examined by western blot in oesophageal cancer tissue $(T)$ and normal squamous epithelium $(N)$ obtained from the same patient. Whole cell lysates of MCF7 and recombinant protein of each CKI 8 and CK8 were used as positive controls.
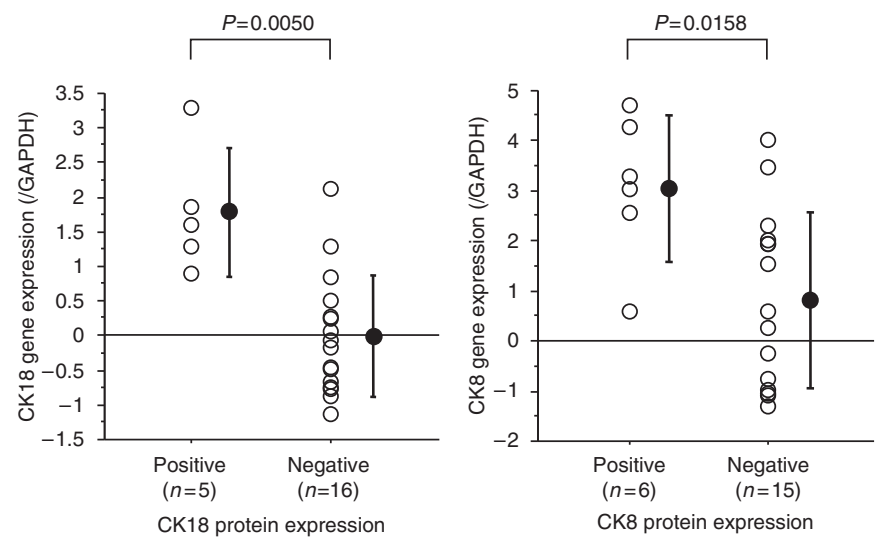

Figure 3 Relationship between protein expression and mRNA expression of CKI8 and CK8. The relative ratio of CKI8 mRNA expression in CKI8positive tumours $(n=5)$ was significantly higher than in CKI8-negative tumours $(n=16)$. A similar trend was observed for CK8 mRNA expression in CK8positive $(n=6)$ and CK8-negative $(n=15)$ tumours. Data are mean \pm s.d.

Table 3 Correlation between CK I 8/CK8 and various clinicopathological parameters

\begin{tabular}{|c|c|c|c|c|c|c|}
\hline & \multicolumn{3}{|c|}{ CKI 8} & \multicolumn{3}{|c|}{ СК8 } \\
\hline & Positive & Negative & $P$ & Positive & Negative & $P$ \\
\hline \multicolumn{7}{|l|}{ Age } \\
\hline$<65$ & 55 & 61 & 0.1615 & 53 & 63 & 0.0922 \\
\hline$>65$ & 35 & 59 & & 32 & 62 & \\
\hline \multicolumn{7}{|l|}{ Gender } \\
\hline Male & 83 & 104 & 0.2654 & 77 & 110 & 0.6555 \\
\hline Female & 7 & 16 & & 8 & 15 & \\
\hline \multicolumn{7}{|l|}{ Histopathology } \\
\hline Well of & 7 & 41 & $<0.0001$ & 5 & 43 & $<0.000 \mid$ \\
\hline Mod, poor & 83 & 79 & & 80 & 82 & \\
\hline \multicolumn{7}{|l|}{ Location } \\
\hline Upper & 13 & 11 & 0.2758 & 14 & 10 & 0.0766 \\
\hline Middle, lower & 77 & 109 & & 71 & 115 & \\
\hline \multicolumn{7}{|c|}{ Neo-adjuvant chemotherapy } \\
\hline Present & 56 & 54 & 0.0175 & 52 & 58 & 0.0485 \\
\hline Absent & 34 & 66 & & 33 & 67 & \\
\hline \multicolumn{7}{|l|}{ pT } \\
\hline TO-2 & 24 & 50 & 0.0287 & 29 & 45 & 0.8831 \\
\hline $\mathrm{T} 3-4$ & 66 & 70 & & 56 & 80 & \\
\hline \multicolumn{7}{|l|}{ Number of $p N$} \\
\hline$<4$ & 50 & 94 & 0.0005 & 51 & 93 & 0.0340 \\
\hline$>4$ & 40 & 26 & & 34 & 32 & \\
\hline \multicolumn{7}{|l|}{ pStage } \\
\hline 1 & 5 & 13 & 0.0045 & 8 & 10 & 0.6488 \\
\hline 2 & 22 & 53 & & 26 & 49 & \\
\hline 3 & 36 & 30 & & 29 & 37 & \\
\hline 4 & 27 & 24 & & 22 & 29 & \\
\hline
\end{tabular}

Well, mod, poor = well, moderately, and poorly differentiated squamous cell carcinoma; upper, middle, lower = upper, middle, lower, and thoracic oesophagus. pT, pN, pStage (pathological classification) based on TNM classification.

\section{Correlation between cytokeratins 18 and 8 expression and clinicopathological parameters}

Table 3 lists the correlations between CK18 and CK8 expression and various clinicopathological parameters. In comparison with 
CK18-negative OSCCs, the proportion of CK18-positive tumours was significantly higher among moderately poorly differentiated OSCCs $(65.8 \%$ vs $92.2 \%$, respectively, $P<0.001)$, patients treated with NACT $(45.0 \%$ vs $62.2 \%$, respectively, $P=0.018)$, advanced pathological $\mathrm{T}$ stage $(\mathrm{pT} 3,4)(58.3 \%$ vs $73.3 \%$, respectively, $P=0.029)$, large number $(\geqslant 4)$ of pathologically positive lymph nodes $(21.7 \%$ vs $44.4 \%$, respectively, $P=0.001)$, and advanced pathological stage (pStage III/IV) $(45.0 \%$ vs $70.0 \%$, respectively, $P=0.0045)$. On the other hand, there were no significant correlations among CK18 expression and other parameters listed in Table 3, such as age, gender, tumour location, and clinical response to NACT.

Similarly, compared with CK8-negative tumours, the proportion of CK8-positive cases was significantly higher among moderately poorly differentiated OSCCs $(65.6 \%$ vs $94.1 \%$, respectively, $P<0.001)$, patients treated with NACT $(46.4 \%$ vs $61.2 \%$, respectively, $P=0.0485)$, and large number $(\geqslant 4)$ of pathologically positive lymph nodes $(25.6 \%$ vs $40.0 \%$, respectively, $P=0.0340)$. On the other hand, there were no significant correlations among CK8 expression and other parameters listed in Table 3, such as age, gender, tumour location, $\mathrm{pT}$, pStage, and clinical response to NACT.

\section{Survival rates}

Disease recurrence after curative resection was diagnosed in 90 $(45.2 \%)$ of 199 patients with curative resection (R0) and the mean time to recurrence was 8.8 months. Deaths because of primary cancer occurred in $83(39.5 \%)$ of the 210 patients and the mean time between surgical resection and death was 15.3 months. The 5-year DFS and OS rates for all patients were $51.6 \%$ and $54.0 \%$, respectively. Patients with CK18-positive tumours had significantly poorer DFS and OS than those with CK18-negative tumours (5-year DFS: $30.6 \%$ vs $65.8 \%$, respectively, $P<0.001$, 5-year OS: $32.8 \%$ vs $68.4 \%$, respectively, $P<0.001$ ) (Figure $4 \mathrm{~A}$ ). CK8-positive tumours were also significantly associated with poorer DFS and OS than CK8-negative ones (5-year DFS: $40.0 \%$ vs 59.0\%, respectively, $P=0.043$, 5-year OS: $39.6 \%$ vs $63.9 \%$, respectively, $P=0.017$ ) (Figure 4B). There was significant prognostic difference in survival between CK18-positive and -negative groups according to pStage II (5-year DFS: $33.6 \%$ vs $70.6 \%$, respectively, $P=0.033$ ) and pStage III (5-year DFS: $27.8 \%$ vs 67.9\%, respectively, $P=0.006$ ), but not at pStage I (5-year DFS: $100 \%$ vs $92.3 \%$, respectively, NS) or pStage IV (5-year DFS: $18.2 \%$ vs $35.0 \%$, respectively, $P=0.579$ ) (Figure 4C).

Univariate analysis using Cox's proportional hazard model showed that the following parameters correlated significantly with DFS: pT stage, number of pathologically positive lymph nodes (pN number), lymphatic invasion (ly), venous invasion (v), CK18 expression, and CK8 expression (Table 4). Finally, the above parameters were entered into multivariate analysis. The results showed that $\mathrm{pT}, \mathrm{pN}$ number, and CK18 expression significantly and independently influenced prognosis (i.e., DFS) $(\mathrm{HR}=1.909$, $P=0.020 ; \quad \mathrm{HR}=2.095, \quad P=0.001 ;$ and $\mathrm{HR}=1.879, \quad P=0.004$, respectively, Table 4$)$.

\section{Cytokeratin 18 expression in preoperative biopsy specimens}

In 83 patients, fiberscopic biopsy samples obtained before treatment, which included 2-5 tissue pieces in each patient, were also investigated for CK18 expression. Immunostaining for CK18 was basically similar among the obtained tissue pieces. Immunostaining showed CK18 expression in 47 (56.6\%) cases (Figure 1I). The classification of CK18 immunostaining matched that of surgical specimens in $67(80.7 \%)$ cases. Survival analysis also showed that pretreated CK18-positive tumours were also significantly associated with poorer OS than biopsy CK18-negative ones (5-year OS: $30.4 \%$ vs 62.2\%, respectively, $P=0.045$ ) (Figure 5).

\section{DISCUSSION}

This study showed positive immunoreactivity to CK18 and CK8 in $42.9 \%$ and $40.5 \%$ of the surgical samples of OSCC, with a high concordance rate of IHC classification (82.4\%). Positive CK18 and CK8 expression was significantly associated with pathological factors related to tumour progression (advanced $\mathrm{pT}$, large $\mathrm{pN}$ number, and advanced pStage) and malignant phenotype (poor differentiation). CK18, in particular as a single marker, was identified as an independent prognostic predictor for DFS and OS and to influence prognosis especially in patients with pStage II/III tumours. The prognostic significance of CK18 expression was also confirmed in pretreatment biopsy samples, suggesting its potential suitability for clinical application in the future. To our knowledge, this is the first report that has identified CK18 and CK8 expression as a single predictor of progression and poor prognosis in OSCC patients after curative resection.

Cytokeratins are intermediate filaments and typical epithelial cell markers are expressed in organ-specific and differentiationdependent manners (Kurokawa et al, 2006). Cytokeratin filaments are formed by tetrameric heteropolymers of two different types of CKs (types I and II) (Chu et al, 1993). With respect to their relation with cancer, the expression levels of some CKs, such as CK19, are abundant and stable among tumours, therefore these molecules are considered useful markers for micrometastases or speculation on occult primary cancer (Fujita et al, 2006; Liu et al, 2008). On the other hand, CK expression levels are reported to change dynamically with carcinogenesis, at least in some cases. Such changes include loss of CK7 and acquisition of CK20 in colorectal carcinoma (Park et al, 2002), acquisition of CK7 and loss of CK20 in gastric carcinoma (Park et al, 2002; Kim et al, 2004), or acquisition of $\mathrm{CK} 1,5,6,8,19$ in squamous cell carcinoma (Xu et al, 1995; Chu and Weiss, 2002b; Ikeda et al, 2008). Furthermore, these changes correlated with malignant transformation or metastatic ability and were associated with poor prognosis (Kim et al, 2004). Also in OSCC, earlier reports indicated that CK expression profiles generally change along with malignant changes (Grace et al, 1985; Lam et al, 1995; Takahashi et al, 1995; Viaene and Baert, 1995; Chung et al, 2006), including induction of CK8, 14, 15, 17, 18, 19 expression (Grace et al, 1985; Lam et al, 1995; Takahashi et al, 1995) and loss of CK4, 5, 13 expression (Franke et al, 1981; Banks-Schlegel and Harris, 1984; Takahashi et al, 1995). Among the CKs, we evaluated CK8 and CK18 in this study.

Accumulation of CK8/18 proteins was observed in about $25 \%$ of the cases with dysplasia and half with OSCC, whereas normal squamous epithelium of oesophagus showed no such expression. Thus, CK8/18 expression is considered to be associated with tumour malignancy based on the finding of increased frequency of expression with tumour staging and correlation with unfavourable prognosis. A similar trend was also reported in other malignancies such as head and neck carcinoma (Gires et al, 2006), oral cavity carcinoma (Fillies et al, 2006), and transitional carcinoma of the urinary tract (Schaafsma et al, 1990). In contrast, some CK8/18expressing adenocarcinomas show downregulation of such expression with progression, which correlates with poor outcome, as reported in human breast cancer (Takei et al, 1995; Schaller et al, 1996; Woelfle et al, 2004) and colorectal cancer (Knosel et al, 2006).

What are the functions of $\mathrm{CK} 8 / 18$ proteins? Although the exact roles of these proteins are unknown at this stage, there is evidence to suggest their involvement in invasive or growth properties of tumours (Chu et al, 1993; Raul et al, 2004) and drug resistance (Bauman et al, 1994; Ma et al, 2009). In vitro analysis using CK8/18 
A

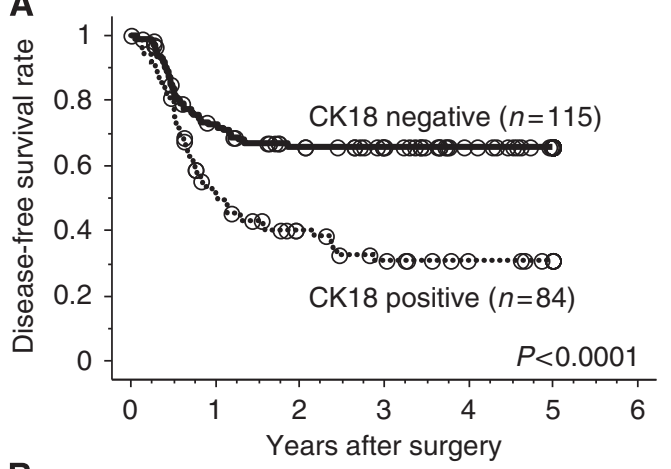

B

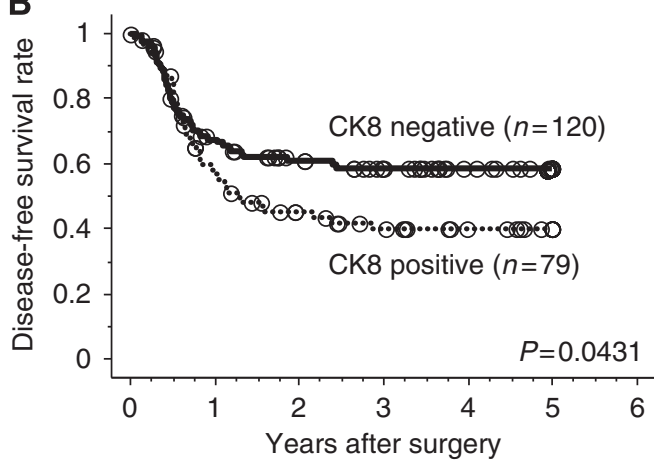

C pStage I
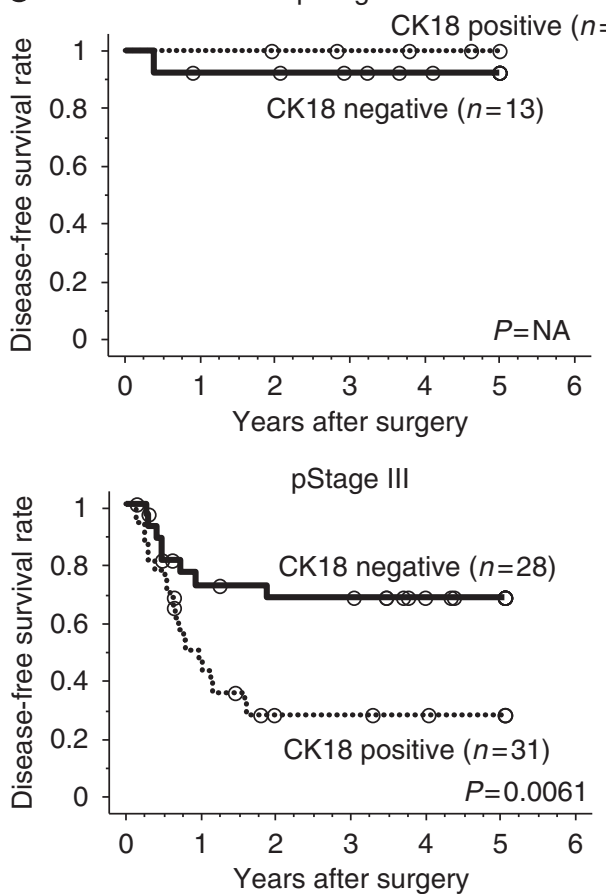
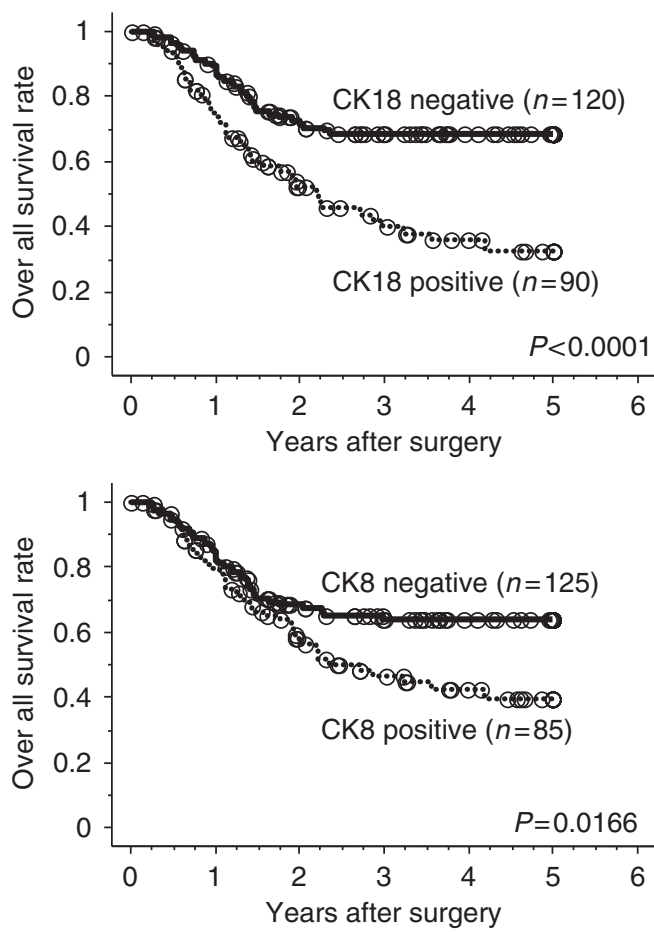

pStage II

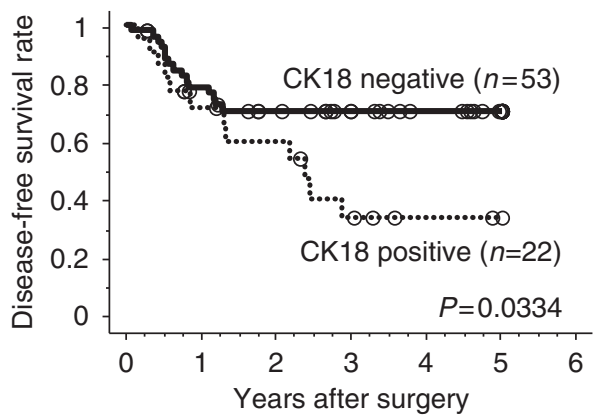

pStage IV

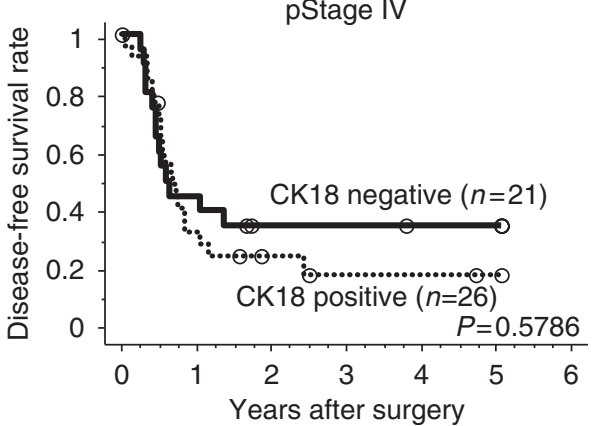

Figure 4 Survival rates according to CKI8 and CK8 expression. (A, B) Disease-free survival curves (left, $n=199$ ) and overall survival curves (right, $n=2$ I 0 ) classified by CKI 8 (A) and CK8 (B) expression for all patients were plotted by Kaplan-Meier method. (C) Disease-free survival curves classified by CKI 8 expression in each pathological stage. Differences between the two groups were evaluated by the log-rank test.

transfection technique showed conflicting results. In one study, mouse L cells transfected with CK8/18 showed enhanced migration and invasion abilities (Chu et al, 1993) whereas in another study transfection of CK18 gene in human breast cancer cells caused marked regression of malignancy (Buhler and Schaller, 2005). Another possibility of the functional roles of these proteins, CK8/18 expression levels may not directly correlate with malignant transformation, but change accompanying with other malignant signals, for example, epithelial-mesenchymal transition (Knosel et al, 2006). As recent evidence showed that oncogenes activating Ras signal-transduction pathways stimulate the expression of CK8 and CK18 genes through transcription factors, such as members of the AP1 (Jun, Fos) and ETS families (Oshima et al, 1996), the expression of $\mathrm{CK} 8 / 18$ may reflect integrated transcriptional 
Table 4 Results of univariate and multivariate survival analyses of disease-free survival by Cox's proportional hazard model

\begin{tabular}{|c|c|c|c|c|}
\hline & $\mathbf{n}$ & HR & $95 \% \mathrm{Cl}$ & $P$ \\
\hline \multicolumn{5}{|l|}{ Univariate survival analysis } \\
\hline Age $(<65 / \geqslant 65)$ & $109 / 90$ & 1.097 & $0.722-1.667$ & 0.6640 \\
\hline Gender (male/female) & |78/21 & 1.522 & $0.703-3.292$ & 0.2862 \\
\hline Histopathology (mod, poor/well) & $152 / 47$ & 1.664 & $0.955-2.900$ & 0.0724 \\
\hline Location (middle, lower/upper) & 179/20 & 1.004 & $0.520-1.938$ & 0.9901 \\
\hline Neo-adjuvant chemotherapy (yes/no) & $101 / 98$ & 1.508 & $0.993-2.29 \mid$ & 0.0542 \\
\hline & $125 / 74$ & 2.781 & $1.689-4.579$ & $<0.0001$ \\
\hline Number of $\mathrm{pN}(\geqslant 4 /<4)$ & $60 / 139$ & 3.098 & $2.036-4.713$ & $<0.0001$ \\
\hline ly (present/absent) & $161 / 38$ & 3.074 & $1.486-6.357$ & 0.0024 \\
\hline$\vee($ present/absent) & $88 / 111$ & 1.542 & $1.019-2.333$ & 0.0405 \\
\hline CKI8 expression (positive/negative) & $84 / 115$ & 2.388 & $1.565-3.643$ & $<0.000$ \\
\hline CK8 expression (positive/negative) & $79 / 120$ & 1.528 & $1.010-2.313$ & 0.0448 \\
\hline
\end{tabular}

Multivariate survival analysis

pT $(T 3,4 / T I, 2)$

Number of $\mathrm{pN}(\geqslant 4 /<4)$

ly (present/absent)

$\checkmark$ (present/absent)

CKI8 expression (positive/negative) $\begin{array}{llll}125 / 74 & 1.909 & 1.107-3.209\end{array}$

$\begin{array}{lll}60 / 139 & 2.095 & 1.347-3.257\end{array}$

$161 / 38 \quad 1.976 \quad 0.915-4.264$

$88 / 111 \quad 1.023 \quad 0.655-1.599$

$84 / 115 \quad 1.879 \quad 1.219-2.897$
0.0199

0.0010

0.0829

0.9197

0.0043
For abbreviations, see Tables $1-3$; ly=lymphatic invasion; $v=$ venous invasion $\mathrm{HR}=$ hazard ratio; $95 \% \mathrm{Cl}=95 \%$ confidence interval.

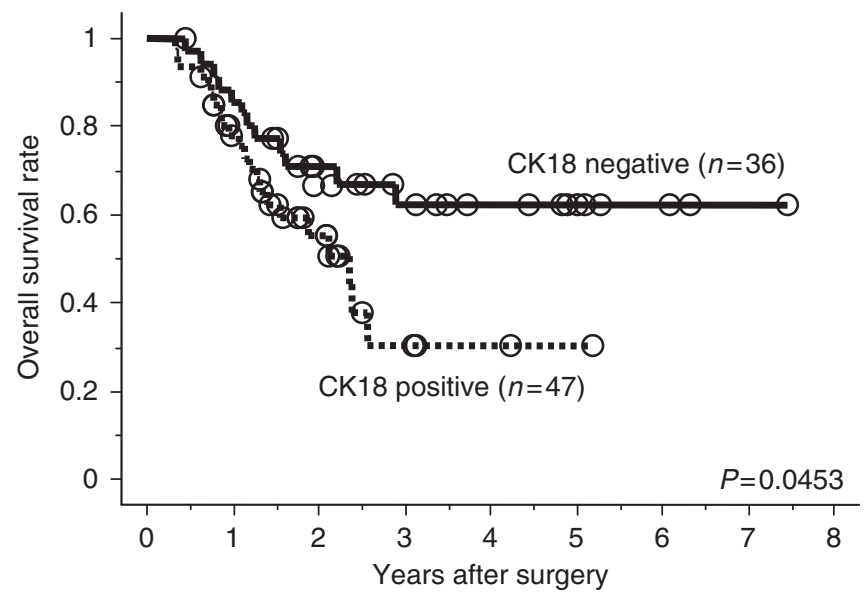

Figure 5 Survival rates according to CKI 8 expression in pretreatment biopsy samples. Overall survival curves $(n=83)$ classified by CKI 8 expression were plotted by Kaplan-Meier method. Differences between the two groups were evaluated by the log-rank test.

activation of such transcription factors. In this study, there was a strong correlation between the expression of CK8 and CK18 with regard to both protein accumulation and mRNA level, which could indicate that $\mathrm{CK} 8$ and $\mathrm{CK} 18$ are regulated by some common signals. Further investigation is necessary to explore the regulatory mechanisms of CK8 and CK18 expression.

Survival analyses based on pathological stage by TNM classification (Sobin, 2002) were comparable to those of earlier reports of OSCC in Japan. In this study, CK18 had a significant prognostic value especially in patients with pStage II/III tumours, but not with pStage I/IV OSCCs. This finding suggests that the prognosis of patients with pStage II/III tumours is affected by malignant potentiality whereas that of pStage I/IV tumours is rather influenced by anatomical staging. Therefore, for the prediction of prognosis of patients with pStage II/III tumours, it might be useful to integrate CK18 expression level evaluation into pathological TNM classification.

With regard to the treatment strategies of OSCC patients, the use of CK18 expression and pathological TNM classification (Sobin, 2002) could be a valuable guide in decision making regarding adjuvant therapy. For example, postoperative chemotherapy might be useful for CK18-expressing pStage II/III tumours and pStage IV tumours regardless of $\mathrm{CK} 18$ expression, but not for pStage I tumours and CK18-negative pStage II/III tumours. Furthermore, because neo-adjuvant treatment has recently become the standard of care for patients with advanced OSCC, evaluation of pretreatment biopsy specimens is important. Our results indicated that though CK18 protein expression varied among OSCC, it was abundant and stable in each OSCC; oesophageal squamous cell epithelium is intrinsically negative for CK8/18 expression and almost all cancer tissue specimens positive for CK8/18 expression contained more than $50 \%$ immuno-positive cells relative to the total number of cancer cells, though in a few cases CK8/18-positive cells constituted only $10-50 \%$ of cancer cells. On the other hand, among CK8/18-positive cases, survival of patients with more frequent (more than $75 \%$ ) expression of CK8/18 tended to show poorer prognosis but with no significant difference. Thus, our classification can be considered both practical and useful, and evaluation in biopsy specimen well represented the characteristic of the whole tumour. Usage of biopsy specimen would highly enhance the application of this molecule in clinical activity; as clinical staging can be performed precisely following recent advances in imaging modalities, it is possible that decisions regarding selection of neo-adjuvant therapy are based in the future on clinical TNM staging and CK18 expression level in pretreatment biopsy specimens. It should be noted that this study was based on analysis of squamous cell carcinoma, which is the dominant histopathological type in East Asian countries. Therefore, our results are not applicable to adenocarcinomas of the oesophagus, which is the major histopathological type in Western countries, which are characterised by overexpression of CK8 and CK18.

In conclusion, the results of this study showed that CK18 and CK8 expression as determined by IHC could be potentially a useful predictor of prognosis of OSCC patients after curative resection. These results may lead to the design of new treatment strategies for OSCC based on manipulation of CK18 and CK8 expression.

\section{REFERENCES}

Akita H, Doki Y, Miyata H, Hirao T, Yano M, Takachi K, Miyashiro I, Sasaki Y, Ishikawa O, Ohigashi H, Imaoka S (2006) Clinical significance of the second cycle response to cisplatin-based chemotherapy as preoperative treatment for esophageal squamous cell carcinoma. J Surg Oncol 93: $401-409$

Ando N, Iizuka T, Ide H, Ishida K, Shinoda M, Nishimaki T, Takiyama W, Watanabe $\mathrm{H}$, Isono K, Aoyama N, Makuuchi H, Tanaka O, Yamana H, Ikeuchi S, Kabuto T, Nagai K, Shimada Y, Kinjo Y, Fukuda H (2003) Surgery plus chemotherapy compared with surgery alone for localized squamous cell carcinoma of the thoracic esophagus: a Japan Clinical Oncology Group Study - JCOG9204. J Clin Oncol 21: $4592-4596$

Banks-Schlegel SP, Harris CC (1984) Aberrant expression of keratin proteins and cross-linked envelopes in human esophageal carcinomas. Cancer Res 44: 1153-1157

Bartek J, Vojtesek B, Staskova Z, Bartkova J, Kerekes Z, Rejthar A, Kovarik J (1991) A series of 14 new monoclonal antibodies to keratins: characterization and value in diagnostic histopathology. J Pathol 164: $215-224$ 
Bauman PA, Dalton WS, Anderson JM, Cress AE (1994) Expression of cytokeratin confers multiple drug resistance. Proc Natl Acad Sci USA 91: $5311-5314$

Buhler H, Schaller G (2005) Transfection of keratin 18 gene in human breast cancer cells causes induction of adhesion proteins and dramatic regression of malignancy in vitro and in vivo. Mol Cancer Res 3: 365-371

Chu PG, Weiss LM (2002a) Keratin expression in human tissues and neoplasms. Histopathology 40: 403-439

Chu PG, Weiss LM (2002b) Expression of cytokeratin 5/6 in epithelial neoplasms: an immunohistochemical study of 509 cases. Mod Pathol 15: $6-10$

Chu YW, Runyan RB, Oshima RG, Hendrix MJ (1993) Expression of complete keratin filaments in mouse $\mathrm{L}$ cells augments cell migration and invasion. Proc Natl Acad Sci USA 90: 4261-4265

Chu YW, Seftor EA, Romer LH, Hendrix MJ (1996) Experimental coexpression of vimentin and keratin intermediate filaments in human melanoma cells augments motility. Am J Pathol 148: 63-69

Chu YW, Yang PC, Yang SC, Shyu YC, Hendrix MJ, Wu R, Wu CW (1997) Selection of invasive and metastatic subpopulations from a human lung adenocarcinoma cell line. Am J Respir Cell Mol Biol 17: 353-360

Chung JY, Braunschweig T, Hu N, Roth M, Traicoff JL, Wang QH, Knezevic V, Taylor PR, Hewitt SM (2006) A multiplex tissue immunoblotting assay for proteomic profiling: a pilot study of the normal to tumor transition of esophageal squamous cell carcinoma. Cancer Epidemiol Biomarkers Prev 15: $1403-1408$

Cintorino M, Tripod SA, Santopietro R, Antonio P, Lutfi A, Chang F, Syrjanen S, Shen Q, Tosi P, Syrjanen K (2001) Cytokeratin expression patterns as an indicator of tumour progression in oesophageal squamous cell carcinoma. Anticancer Res 21: 4195-4201

Debus E, Moll R, Franke WW, Weber K, Osborn M (1984) Immunohistochemical distinction of human carcinomas by cytokeratin typing with monoclonal antibodies. Am J Pathol 114: $121-130$

Fillies T, Werkmeister R, Packeisen J, Brandt B, Morin P, Weingart D, Joos U, Buerger H (2006) Cytokeratin 8/18 expression indicates a poor prognosis in squamous cell carcinomas of the oral cavity. $B M C$ Cancer 6: 10

Fiorica F, Di Bona D, Schepis F, Licata A, Shahied L, Venturi A, Falchi AM, Craxi A, Camma C (2004) Preoperative chemoradiotherapy for oesophageal cancer: a systematic review and meta-analysis. Gut 53: $925-930$

Franke WW, Schiller DL, Moll R, Winter S, Schmid E, Engelbrecht I, Denk H, Krepler R, Platzer B (1981) Diversity of cytokeratins. Differentiation specific expression of cytokeratin polypeptides in epithelial cells and tissues. J Mol Biol 153: 933-959

Fujita Y, Terashima M, Hoshino Y, Ohtani S, Kashimura S, Kanzaki N, Osuka F, Kogure M, Gotoh M (2006) Detection of cancer cells disseminated in bone marrow using real-time quantitative RT-PCR of CEA, CK19, and CK20 mRNA in patients with gastric cancer. Gastric Cancer 9: $308-314$

Gires O, Mack B, Rauch J, Matthias C (2006) CK8 correlates with malignancy in leukoplakia and carcinomas of the head and neck. Biochem Biophys Res Commun 343: 252-259

Grace MP, Kim KH, True LD, Fuchs E (1985) Keratin expression in normal esophageal epithelium and squamous cell carcinoma of the esophagus. Cancer Res 45: $841-846$

Hendrix MJ, Seftor EA, Chu YW, Trevor KT, Seftor RE (1996) Role of intermediate filaments in migration, invasion and metastasis. Cancer Metastasis Rev 15: 507-525

Hesse M, Magin TM, Weber K (2001) Genes for intermediate filament proteins and the draft sequence of the human genome: novel keratin genes and a surprisingly high number of pseudogenes related to keratin genes 8 and 18. J Cell Sci 114: 2569-2575

Ikeda K, Tate G, Suzuki T, Mitsuya T (2008) Coordinate expression of cytokeratin 8 and cytokeratin 17 immunohistochemical staining in cervical intraepithelial neoplasia and cervical squamous cell carcinoma: an immunohistochemical analysis and review of the literature. Gynecol Oncol 108: $598-602$

Johansson A, Sandstrom P, Ullen A, Behravan G, Erlandsson A, Levi M, Sundstrom B, Stigbrand T (1999) Epitope specificity of the monoclonal anticytokeratin antibody TS1. Cancer Res 59: 48-51

Kaklamanos IG, Walker GR, Ferry K, Franceschi D, Livingstone AS (2003) Neoadjuvant treatment for resectable cancer of the esophagus and the gastroesophageal junction: a meta-analysis of randomized clinical trials. Ann Surg Oncol 10: 754-761
Kim MA, Lee HS, Yang HK, Kim WH (2004) Cytokeratin expression profile in gastric carcinomas. Hum Pathol 35: 576-581

Knosel T, Emde V, Schluns K, Schlag PM, Dietel M, Petersen I (2006) Cytokeratin profiles identify diagnostic signatures in colorectal cancer using multiplex analysis of tissue microarrays. Cell Oncol 28: $167-175$

Kurokawa I, Urakawa Y, Senba Y, Kawabata E, Nishimura K, Omoto Y, Tokime K, Mizutani H, Tsubura A (2006) Keratin profiles may differ between intraepidermal and intradermal invasive eccrine porocarcinoma. Oncol Rep 16: 473-477

Lam KY, Loke SL, Shen XC, Ma LT (1995) Cytokeratin expression in nonneoplastic oesophageal epithelium and squamous cell carcinoma of the oesophagus. Virchows Arch 426: 345-349

Liu Z, Jiang M, Yan F, Xu L, Zhao J, Ju H (2008) Multipoint quantification of multimarker genes in peripheral blood and micrometastasis characteristic in peri-operative esophageal cancer patients. Cancer Lett 261: $46-54$

Ma Y, Ding Z, Qian Y, Wan YW, Tosun K, Shi X, Castranova V, Harner EJ, Guo NL (2009) An integrative genomic and proteomic approach to chemosensitivity prediction. Int J Oncol 34: 107-115

Makino T, Doki Y, Miyata H, Yasuda T, Yamasaki M, Fujiwara Y, Takiguchi S, Higuchi I, Hatazawa J, Monden M (2008) Use of (18)F-fluorodeoxyglucose-positron emission tomography to evaluate responses to neoadjuvant chemotherapy for primary tumor and lymph node metastasis in esophageal squamous cell carcinoma. Surgery 144: 793-802

Matsuyama J, Doki Y, Yasuda T, Miyata H, Fujiwara Y, Takiguchi S, Yamasaki M, Makari Y, Matsuura N, Mano M, Monden M (2007) The effect of neoadjuvant chemotherapy on lymph node micrometastases in squamous cell carcinomas of the thoracic esophagus. Surgery 141: $570-580$

Miyata H, Doki Y, Yamamoto H, Kishi K, Takemoto H, Fujiwara Y, Yasuda $\mathrm{T}$, Yano $\mathrm{M}$, Inoue $M$, Shiozaki $\mathrm{H}$, Weinstein IB, Monden M (2001) Overexpression of CDC25B overrides radiation-induced G2-M arrest and results in increased apoptosis in esophageal cancer cells. Cancer Res 61: $3188-3193$

Moll R, Franke WW, Schiller DL, Geiger B, Krepler R (1982) The catalog of human cytokeratins: patterns of expression in normal epithelia, tumors and cultured cells. Cell 31: 11-24

Oshima RG, Baribault H, Caulin C (1996) Oncogenic regulation and function of keratins 8 and 18. Cancer Metastasis Rev 15: $445-471$

Park SY, Kim HS, Hong EK, Kim WH (2002) Expression of cytokeratins 7 and 20 in primary carcinomas of the stomach and colorectum and their value in the differential diagnosis of metastatic carcinomas to the ovary. Hum Pathol 33: 1078-1085

Raul U, Sawant S, Dange P, Kalraiya R, Ingle A, Vaidya M (2004) Implications of cytokeratin $8 / 18$ filament formation in stratified epithelial cells: induction of transformed phenotype. Int J Cancer 111: $662-668$

Schaafsma HE, Ramaekers FC, van Muijen GN, Lane EB, Leigh IM, Robben H, Huijsmans A, Ooms EC, Ruiter DJ (1990) Distribution of cytokeratin polypeptides in human transitional cell carcinomas, with special emphasis on changing expression patterns during tumor progression. Am J Pathol 136: 329-343

Schaller G, Fuchs I, Pritze W, Ebert A, Herbst H, Pantel K, Weitzel H, Lengyel E (1996) Elevated keratin 18 protein expression indicates a favorable prognosis in patients with breast cancer. Clin Cancer Res 2: $1879-1885$

Schussler MH, Skoudy A, Ramaekers F, Real FX (1992) Intermediate filaments as differentiation markers of normal pancreas and pancreas cancer. Am J Pathol 140: 559-568

Shimada H, Nabeya Y, Okazumi S, Matsubara H, Shiratori T, Gunji Y, Kobayashi S, Hayashi H, Ochiai T (2003) Prediction of survival with squamous cell carcinoma antigen in patients with resectable esophageal squamous cell carcinoma. Surgery 133: 486-494

Sobin LH, Wittekind C (2002) TNM Classification of Malignant Tumors, 6th edn, John Wiley and Sons, Inc: New York

Southgate J, Harnden P, Trejdosiewicz LK (1999) Cytokeratin expression patterns in normal and malignant urothelium: a review of the biological and diagnostic implications. Histol Histopathol 14: $657-664$

Takahashi H, Shikata N, Senzaki H, Shintaku M, Tsubura A (1995) Immunohistochemical staining patterns of keratins in normal oesophageal epithelium and carcinoma of the oesophagus. Histopathology 26: $45-50$ 
CKI 8/CK8 associated with poor outcome in oesophageal cancer

$\mathrm{T}$ Makino et al

1306

Takei H, Iino Y, Horiguchi J, Kanoh T, Takao Y, Oyama T, Morishita Y (1995) Immunohistochemical analysis of cytokeratin \#8 as a prognostic factor in invasive breast carcinoma. Anticancer Res 15: $1101-1105$

Tepper J, Krasna MJ, Niedzwiecki D, Hollis D, Reed CE, Goldberg R, Kiel K, Willett C, Sugarbaker D, Mayer R (2008) Phase III trial of trimodality therapy with cisplatin, fluorouracil, radiotherapy, and surgery compared with surgery alone for esophageal cancer: CALGB 9781. J Clin Oncol 26: $1086-1092$

Trask DK, Band V, Zajchowski DA, Yaswen P, Suh T, Sager R (1990) Keratins as markers that distinguish normal and tumor-derived mammary epithelial cells. Proc Natl Acad Sci USA 87: $2319-2323$
Viaene AI, Baert JH (1995) Expression of cytokeratin-mRNAs in squamouscell carcinoma and balloon-cell formation of human oesophagea epithelium. Histochem J 27: 69-78

Woelfle U, Sauter G, Santjer S, Brakenhoff R, Pantel K (2004) Downregulated expression of cytokeratin 18 promotes progression of human breast cancer. Clin Cancer Res 10: 2670-2674

Xu XC, Lee JS, Lippman SM, Ro JY, Hong WK, Lotan R (1995) Increased expression of cytokeratins CK8 and CK19 is associated with head and neck carcinogenesis. Cancer Epidemiol Biomarkers Prev 4: 871-876

Yano M, Takachi K, Doki Y, Miyashiro I, Kishi K, Noura S, Eguchi H, Yamada T, Ohue M, Ohigashi H, Sasaki Y, Ishikawa O, Imaoka S (2006) Preoperative chemotherapy for clinically node-positive patients with squamous cell carcinoma of the esophagus. Dis Esophagus 19: 158-163 